\title{
Concentrations of Neonicotinoids and their Characteristic Metabolites in Blood Samples from South China: Association with Liver Cancer
}

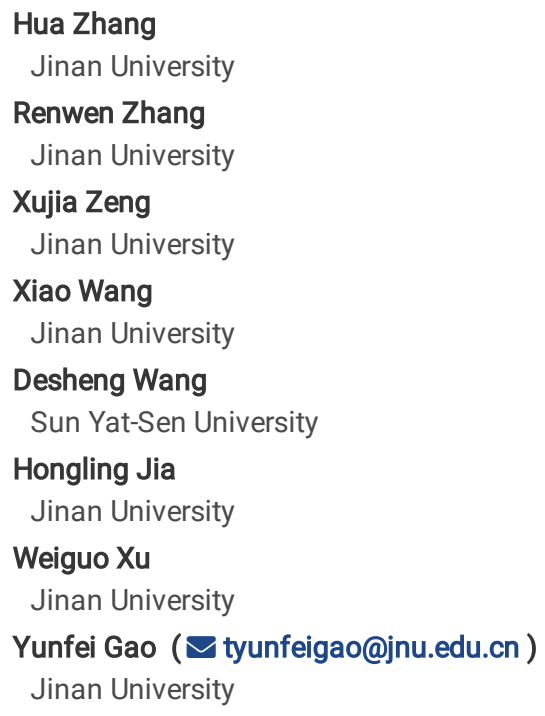




\section{Abstract}

Neonicotinoid insecticides (NEOs) are commonly applied for pest control in China and around the world. They have potential toxicity to bees, birds, mammals, and even human being. However, limited studies have explored the associations between NEOs exposure and disease. In the present study, we detected six parent NEOs (p-NEOs), including acetamiprid, thiacloprid, dinotefuran, clothianidin, imidacloprid, and thiamethoxam, and five characteristic metabolites (m-NEOs), including 5-hydroxy-imidacloprid (5-OH-IMI), olefin-imidacloprid (Of-IMI), N-desmethyl-acetamiprid, 1-methyl-3(tetrahydro-3-furylmethyl) guanidine and 1-methyl-3-(tetrahydro-3-furyl methyl) urea, in blood samples collected from healthy ( $n=100)$ and liver cancer $(n=274)$ populations in South China. NEOs were frequently detected (61-94\%) in blood samples, with median concentrations ranging from 0.19 $\mathrm{ng} / \mathrm{mL}$ to $1.28 \mathrm{ng} / \mathrm{mL}$ and $0.20 \mathrm{ng} / \mathrm{mL}$ to $2.03 \mathrm{ng} / \mathrm{mL}$ for healthy and liver cancer populations, respectively. Of-IMI was the most abundant NEOs in healthy and liver cancer populations, accounting for $23.4 \%$ and $20.7 \%$, respectively. Significant positive correlations among most $\mathrm{m}$-NEOs concentrations were found, and associations between m-NEOs and their corresponding p-NEOs were positively correlated. These findings indicated that the sources of m-NEOs were both endogenous and exogeneous. Females had higher median concentrations of NEOs and their metabolites than males. Moreover, associations between the concentrations of p-NEOs and m-NEOs and liver cancer were found (odds ratio $=2.33-9.02,95 \%$ confidence interval $=0.31-22.7, p<0.05$ ), indicating that human exposure to NEOs and their metabolites might increase the odds of liver cancer prevalence. This study is the first work to document 5-OH-IMI and DN in blood samples collected from South China.

\section{Introduction}

Neonicotinoid insecticides (NEOs), such as imidacloprid (IMI), clothianidin (CLO), thiacloprid (THI), thiamethoxam (THIX), acetamiprid (ACE), and dinotefuran (DIN) (Figure S1), are widely used for pest control in agricultural production around the world because of their broad-spectrum insecticidal activity, unique mode of action (i.e., nicotinic acetylcholine receptors), and lower toxicity to non-target organisms (Simon-Delso et al. 2015; Song et al. 2018; Tomizawa and Casida 2005; Zhang et al. 2019). Due to their high water solubility and systemic properties, NEOs can be absorbed by the roots and then translocated to almost every tissue of the plant; thus, they are difficult to remove from vegetables and fruits through washing or peeling (Franka and Tooker 2020; Zhang et al. 2019; Zhang et al. 2020). Previous studies reported that NEO exposure through dietary intake might pose potential health risk (Chen et al. 2020; Lu et al. 2018; Lu et al. 2020). Moreover, several in vitro and in vivo studies suggested that NEOs could be toxic to mammals and exert reproductive, neurological, genotoxic, and hepatic effects (Cimino et al. 2017; Han et al. 2018; Wang et al. 2018). Therefore, the health risks of human NEO exposure need to be assessed.

Several biomonitoring studies reported the concentrations of parent NEOs ( $p$-NEOs) in human matrices (i.e., urine and blood) from China (Wang et al. 2020; Xu et al. 2021; Zhang et al. 2019; Zhang et al. 2021a), the USA (Li et al. 2020a; Ospina et al. 2019), and Japan (Osaka et al. 2016; Ueyama et al. 2015). Xu et al. (2021) documented the concentrations of six p-NEOs in paired urine and blood samples from 196 university students in Guangdong Province, China. Their results indicated that NEOs were widely detected in urine (67-91\%) and blood (64-91\%) samples. Wang et al. (2020) analyzed the levels of 10 p-NEOs in 408 urine samples from Wuhan, Central China, and found that p-NEOs were frequently detected in human urine, with detection rates of $69-100 \%$. Furthermore, higher detection rates (92-99\%) were showed in one recent study which reported six p-NEO concentrations in 324 urine samples from 13 cities of China (Zhang et al. 2019). These findings indicate that the Chinese population is widely exposed to NEOs.

After exposure, p-NEOs could be coverted into specific metabolites through phase I reaction in animals (Casida 2011; Ford and Casida 2006a, b). Several NEO metabolites (m-NEOs) have been documented in human matrices (Li et al. 2020a; Ospina et al. 2019; Song et al. 2020; Xu et al. 2021; Zhang et al. 2021a,b,c; N. Zhang et al. 2021). For instance, N-desmethyl ACE (ACE-dm), 5-hydroxy IMI (5-OH-IMI), and 1-methyl-3-(tetrahydro-3furylmethyl) urea (UF) were measured in human saliva, periodontal blood, and tooth samples from South China, with median concentrations of 0.07 to $1.20 \mathrm{ng} / \mathrm{mL}$ or $\mathrm{ng} / \mathrm{g}$ (Zhang et al. 2021b; N. Zhang et al. 2021). Olefin-IMI (Of-IMI) was frequently detected in human urine and blood samples from China, with median level of 0.48 to $1.15 \mathrm{ng} / \mathrm{mL}$ (Song et al. 2020; Wang et al. 2020; Xu et al. 2021). In addition, 1-methyl-3-(tetrahydro-3-furylmethyl) guanidine (DN) was measured in human urine samples $(n=275)$ from China, and the median concentration was $0.42 \mathrm{ng} / \mathrm{mL}(\mathrm{Song}$ et al. 2020). Previous studies have demonstrated that m-NEOs were more toxic than their corresponding p-NEOs (Casida 2011; Honda et al. 2006; Marfo et al. 2015; Suchail et al. 2001; Suchail et al. 2003; N. Zhang et al. 2021; Zhang et al. 2021C). For example, the acute and chronic toxicity of 5-OH-IMI and Of-IMI in honey bees was higher than that of the parent compound IMI (Suchail et al. 2001; Suchail et al. 2003). DN and UF were more toxic to vertebrates than DIN (Casida 2011; Honda et al. 2006). Compared with ACE, human ACE-dm exposure levels were associated with increased prevalence of neurological symptoms and periodontitis (Marfo et al. 2015; N. Zhang et al. 2021). Moreover, m-NEOs were frequently detected in foodstuff (Chen et al. 2020; D. Li et al. 2020) and environmental matrices (Wan et al. 2019; Wan et al. 2020; Wang et al. 2019; Zhang et al. 2021a). Previous studies showed that m-NEOs in humans might not only be from endogenous but also from exogenous sources (Song et al. 2020). Therefore, human exposure to m-NEOs is a matter of concern.

Cancer is a multifactorial disease attributed by radiation, lifestyle, smoking, viruses, and environmental pollutants (i.e., pesticides) (Hazarika and Hazarika 2013). Liver cancer ranks the sixth of most diagnosed cancer and the second most common malignancy (Chen and Zhang 2011; Fu and Wang 2018). Pesticide exposure was regarded as a critical environmental risk factor associated with liver cancer development (de Brito Sa Stoppelli and Crestana 2005; Jaga and Dharmani 2005; Parrón et al. 2014). For example, the association between liver cancer and organochlorine pesticides was observed among whites in the USA (Cocco et al. 2000; Parrón et al. 2014; Vopham et al. 2017). One study from China showed that exposure to organochlorine pesticides was an important risk factor of hepatocellular carcinoma (Zhao et al. 2012). Another study from China reported that long and short-term pesticide exposure adversely affected blood cells, the liver, and the peripheral nervous system (Hu et al. 2015). Approximately 360,000

Page 2/16 
incident cases and 350,000 deaths of liver cancer, occur every year in China (Chen and Zhang 2011). Therefore, whether human exposure to NEOs and their metabolites increases the risk of liver cancer is worthy to be investigated.

In this study, the concentrations of NEOs (i.e., IMI, THIX, ACE, CLO, THI, and DIN) and their metabolites (i.e., 5-OH-IMI, Of-IMI, ACE-dm, DN, and UF) were measured in 374 blood samples collected from the general population $(n=100)$ and liver cancer confirmed patient population ( $n=274)$ in South China. The occurrences and characteristics of NEOs and their metabolites were investigated. Moreover, the concentrations of target analytes in the blood and their association with liver cancer were estimated.

\section{Materials And Methods}

\subsection{Chemicals and reagents}

The standards (purity $>98.4 \%$ ) of DIN, IMI, CLO, ACE, THIX, THI, DN, UF, Of-IMI, and ACE-dm were purchased from Dr. Ehrenstorfer (Augsburg, Germany).

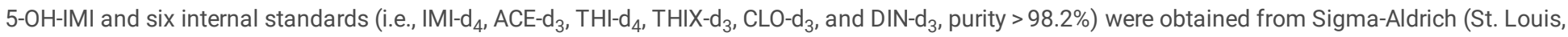
MO). In addition, formic acid, ammonium acetate, and $\beta$-glucuronidase were obtained from Sigma-Aldrich (St. Louis, MO). HPLC grade acetonitrile, methanol, and ethyl acetate were provided by Merck (Darmstadt, Germany). Ultrapure water was obtained from a Millipore system (Billerica, MA).

\subsection{Study areas and sample collection}

This study was approved by the Research Ethics Committee of Jinan University, China. Blood samples were collected in October 2018 and May 2019. All participants in this study provided their informed consent and completed a questionnaire survey (i.e., sociodemographic characteristics and lifestyles). Three hundred seventy-four participants from Guangdong, China were randomly selected. Among them, 274 were liver cancer patients, while the remaining were healthy. All of the participants had no occupational NEO exposure. The mean age of donors was 55 years (range: 11-91 years). More details of the participants were listed in Table S1. Before sample collection, all participants were asked to fast. Whole blood samples were collected directly in heparin vacutainers. All samples were immediately stored at $-20^{\circ} \mathrm{C}$ until sample analysis.

\subsection{Analysis of NEOs and their metabolites}

Sample extraction protocol was based on our previous study (Xu et al. 2021). In brief, the internal standard solution (5 ng) was added into $0.5 \mathrm{~mL}$ of serum sample. Then, $0.3 \mathrm{~mL}$ of $1.0 \mathrm{M}$ ammonium acetate buffer (including 82 units of $\beta$-glucuronidase; $\mathrm{pH}=5.3$ ) was fortified. After the sample was incubated at $37^{\circ} \mathrm{C}$ for $12 \mathrm{~h}, 6 \mathrm{~mL}$ of ethyl acetate were used to extract for twice. Then the samples were shaken vigorously for 3 min and then centrifugated for $3 \mathrm{~min}$ at $3000 \times \mathrm{g}$. The extracts were combined and dried with nitrogen. Afterward, $0.5 \mathrm{~mL}$ of methanol was used to dissolve the residues. Finally, the solution was placed in a vial for analysis.

The target analytes were determined by an Agilent 1260 HPLC system (Agilent Technologies Inc., Santa Clara, CA) equipped with a SCIEX 5500 electrospray triple quadrupole mass spectrometer (Applied Biosystems, Foster City, CA) with positive electrospray ionization and multiple reaction monitoring (MRM) modes. More information on the MRM transitions of target analytes was presented in Table S2. Target compounds were separated using Zorbax SB-C18 (100 mm × $2.1 \mathrm{~mm}, 3.5 \mu \mathrm{m}$; Agilent Technologies Inc., Santa Clara, CA) at $25^{\circ} \mathrm{C}$. Acetonitrile (A) and $0.1 \%$ formic acid in ultrapure water (B) were used for the mobile phase with gradient flow (Table S3).

\subsection{Quality assurance and quality control}

To monitor the pollutants from reagents and materials, the blanks (i.e., procedural and instrumental) were injected for every 20 samples. NEOs and their metabolites were not detected in the procedural and instrumental blanks. To check the memory effect, methanol was injected for every 20 samples. Matrix-spiked samples were analyzed by spiking at three levels (i.e., $0.1,1$, and $10 \mathrm{ng} / \mathrm{mL}$ ) of NEOs and their metabolites into randomly selected serum samples. The mean recoveries of serum samples ranged from $70-102 \%$, with intra-day and inter-day RSDs of $1-14 \%$ and $3-19 \%$, respectively.

Because no significant signal enhancement or suppression effects were found in blood samples; we therefore used an 8-point calibration curve (prepared in methanol) ranging from $0.01 \mathrm{ng} / \mathrm{mL}$ to $50 \mathrm{ng} / \mathrm{mL}$, with a regression coefficient ( $r$ ) greater than 0.99 , for quantitative analysis. Meanwhile, the calibration standard ( $10 \mathrm{ng} / \mathrm{mL}$ ) was analyzed for every 20 samples. The limit of quantification (LOQ) and limit of detection (LOD) were regarded as 10 and 3 times the signal-to-noise ratio for the qualitative ion, respectively. The LOQs and LODs of NEOs and their metabolites were presented in Table 1. 
Table 1

Concentrations ( $\mathrm{ng} / \mathrm{mL}$ ) of NEOs and their metabolites in blood samples collected from China.

\begin{tabular}{|c|c|c|c|c|c|c|c|c|c|c|c|c|c|c|c|}
\hline & ACE & IMI & CLO & THI & THIX & DIN & $\begin{array}{l}\sum p- \\
\text { NEOs }\end{array}$ & $\begin{array}{l}5-\mathrm{OH}- \\
\mathrm{IMI}\end{array}$ & $\begin{array}{l}\text { Of- } \\
\text { IMI }\end{array}$ & $\begin{array}{l}\text { ACE- } \\
\mathrm{dm}\end{array}$ & DN & UF & $\begin{array}{l}\sum m- \\
\text { NEOs }\end{array}$ & ¿NEOs & $\mid \mathrm{IMI}_{\mathrm{eq}}$ \\
\hline \multirow[t]{2}{*}{ LOQ } & 0.001 & 0.01 & 0.002 & 0.001 & 0.001 & 0.005 & 0.001 & 0.01 & 0.01 & 0.01 & 0.01 & 0.05 & 0.01 & 0.001 & 0.001 \\
\hline & \multicolumn{15}{|c|}{ Healthy groups $(n=100)$} \\
\hline $\begin{array}{l}\mathrm{DR}(\%) \\
a\end{array}$ & 61 & 80 & 94 & 91 & 83 & 83 & 100 & 82 & 85 & 93 & 86 & 81 & 100 & 100 & 100 \\
\hline median & 0.29 & 0.21 & 0.31 & 0.29 & 0.19 & 0.62 & 3.28 & 0.36 & 1.28 & 0.79 & 0.24 & 0.73 & 3.69 & 7.75 & 23.9 \\
\hline $\mathrm{GM}^{b}$ & 0.04 & 0.10 & 0.21 & 0.14 & 0.11 & 0.28 & 3.17 & 0.20 & 0.74 & 0.46 & 0.19 & 0.40 & 4.28 & 8.29 & 25.5 \\
\hline mean & 0.93 & 0.49 & 0.51 & 0.74 & 0.48 & 0.95 & 4.10 & 0.99 & 2.24 & 1.11 & 0.63 & 1.11 & 6.08 & 10.2 & 31.2 \\
\hline $\min$ & $<$ LOQ & LOQ & LOQ & LOQ & LOQ & LOQ & 0.73 & $<$ LOQ & LOQ & $<$ LOQ & LOQ & LOQ & 0.77 & 1.51 & 6.18 \\
\hline \multirow[t]{2}{*}{$\max$} & 16.7 & 21.6 & 3.63 & 5.41 & 7.11 & 4.64 & 40.8 & 38.1 & 25.7 & 13.5 & 23.6 & 21.9 & 66.6 & 74.7 & 157 \\
\hline & \multicolumn{15}{|c|}{ Liver cancer patients $(n=274)$} \\
\hline DR (\%) & 80 & 79 & 78 & 62 & 61 & 80 & 100 & 75 & 70 & 91 & 68 & 86 & 100 & 100 & 100 \\
\hline median & 0.49 & 0.56 & 0.47 & 0.21 & 0.20 & 0.69 & 4.62 & 0.79 & 2.03 & 1.61 & 0.87 & 1.88 & 12.3 & 23.0 & 44.4 \\
\hline GM & 0.16 & 0.57 & 0.18 & 0.05 & 0.03 & 0.26 & 6.27 & 0.28 & 0.58 & 1.21 & 0.48 & 1.60 & 15.2 & 27.3 & 199 \\
\hline mean & 1.39 & 13.2 & 1.4 & 7.62 & 0.84 & 1.92 & 26.4 & 1.27 & 11.9 & 4.04 & 3.23 & 9.83 & 30.3 & 56.7 & 62.6 \\
\hline $\min$ & $\begin{array}{l}<\mathrm{LOQ} \\
c\end{array}$ & LOQ & LOQ & LOQ & LOQ & LOQ & 0.81 & $<$ LOQ & LOQ & $<$ LOQ & LOQ & LOQ & 0.76 & 2.93 & 9.06 \\
\hline $\max$ & 128 & 427 & 91.1 & 302 & 140 & 133 & 969 & 70.0 & 357 & 76.5 & 142 & 250 & 394 & 1213 & 4661 \\
\hline
\end{tabular}

2.5 Calculation of IMI RPF on the basis of the relative potency factors (RPF) of NEOs and their metabolites

Given the difference in potencies of toxicity effects on human health among individual NEOs, the RPF method was used to normalize each NEOs to IMI $\left(\mathrm{IMI}_{\mathrm{RPF}}\right.$ ) (Chen et al. 2021; D. Li et al. 2020; Lu et al. 2018). The RPF was based on the human toxicity of NEOs compared with the chronic reference dose (cRfD) of IMI (Table S4) as shown in Eq. (1) (Chen et al. 2021; D. Li et al. 2020; Lu et al. 2018).

$$
R P F_{i}=\frac{R f D_{I M I}}{R f D_{i}}
$$

1

where i represents NEOs.

The sum of concentrations of p-NEOs (i.e., DIN, IMI, and ACE) and their corresponding m-NEOs (DN, UF, 5-OH-IMI, Of-IMI, and ACE-dm) were denoted as $\Sigma D I N, \Sigma I M I$, and $\Sigma A C E$, respectively. Moreover, the concentrations of NEOs in each serum sample were summed using Eq. (2) to calculate IMI $\mathrm{RPF}(\mathrm{Chen}$ et al. 2021; D. Li et al. 2020; Lu et al. 2018).

$$
I M I_{e q}(n g / m L)=\Sigma_{i}\left(N E O s \times R P F_{i}\right)=I M I+D I N \times 2.9+C L O \times 5.8+T H I \times 14.2+T H I X \times 9.5+A C E \times 0.8
$$

2

\subsection{Statistical analysis}

Data were analyzed with SPSS version 20.0. Concentrations below the LOQ were denoted as a value equal to half of the LOQ to calculate the geometric mean (GM), median, mean, and range values. The total mass concentrations of p-NEOs, m-NEOs, and NEOs were regarded as $\sum \mathrm{p}-\mathrm{NEO}$, $\sum \mathrm{m}-\mathrm{NEO}$, and $\sum$ NEOs, respectively. The Kolmogorov-Smirnov test was used to test data normality. One-way ANOVA was used to determine the differences between groups for normally distributed data; for other cases, the Mann-Whitney U test was employed. The correlation between two sets of normally distributed data was analyzed by the Pearson correlation coefficient; otherwise, Spearman's rank correlation coefficient was applied. In addition, we used the binary or multivariable-adjusted logistic regression to examine the odds ratios (ORs) and $95 \%$ confidence intervals (Cls) of having liver cancer for increments in concentrations of target analytes in blood samples. $P$-values less than 0.05 were considered as significant. 


\section{Results And Discussion}

\subsection{Occurrences of NEOs and their metabolites in the blood}

The distribution of the levels (median, GM, mean, minimum, and maximum) of p-NEOs and m-NEOs in blood samples were presented in Table 1. NEOs were widely detected in blood samples collected from 100 healthy individuals from South China, and the detection rates ranged from $61-94 \%$ (Table 1). Among the p-NEOs, DIN had the highest median blood concentration $(0.62 \mathrm{ng} / \mathrm{mL})$, followed by CLO $(0.31 \mathrm{ng} / \mathrm{mL})$, ACE $(0.29 \mathrm{ng} / \mathrm{mL})$, and THI (0.29 ng/mL; Table 1). Moreover, DIN was the predominant p-NEOs, accounting for $32.4 \%$ (Fig. 1a). Our results indicated that the population collected for this study had a high concentration of exposure to DIN, CLO, ACE, and THI. A similar pattern was also found in previous study, which suggested that high level of exposure to CLO, ACE, and DIN was observed in Chinese population (Xu et al. 2021). Among the m-NEOs, Of-IMI (1.28 $\mathrm{ng} / \mathrm{mL})$ had the highest median concentration in blood samples, followed by ACE-dm $(0.79 \mathrm{ng} / \mathrm{mL})$ and UF (0.73 ng/mL; Table 1). In addition, Of-IMI was the most abundant m-NEOs (37.6\%; Fig. 1a). Meanwhile, Of-IMI was dominant NEOs in blood samples, accounting for $24.1 \%$, followed by ACE-dm (14.9\%), UF (13.7\%), DIN (11.7\%), and 5-OH-IMI (6.85\%). To our knowledge, this study is the first work to report the concentrations of DN and 5-OH-IMI in blood samples.

NEOs and their metabolites were also commonly measured in 274 liver cancer patients, and the detection frequencies ranged from 61-91\% (Table 1). The median concentrations of p-NEOs in blood samples from the liver cancer population were in the following order: DIN (0.69 $\mathrm{ng} / \mathrm{mL})$, IMI ( 0.56 $\mathrm{ng} / \mathrm{mL}), \operatorname{ACE}(0.49 \mathrm{ng} / \mathrm{mL})$, and CLO $(0.47 \mathrm{ng} / \mathrm{mL}$; Table 1). This pattern was similar to those found in the healthy population. And consistent with the results detected in the healthy population, Of-IMI had the highest median blood level in the liver cancer population (2.03 $\mathrm{ng} / \mathrm{mL}$, accounting for $20.7 \%)$, followed by UF (1.88 ng/mL, 19.2\%) and ACE-dm (1.61 ng/mL, 16.4\%; Table 1 and Fig. 1b). These findings suggested that the concentrations of $\mathrm{m}$ NEOs (i.e., Of-IMI, 5-OH-IMI, ACE-dm, and UF) in blood samples were relatively higher than those of their corresponding p-NEOs (i.e., IMI, ACE, and DIN; Table 1 and Fig. 1). A similar trend was also found in previous studies reported in blood (Xu et al. 2021) and serum samples (Zhang et al. 2021c). Previous studies widely measured m-NEOs in foodstuffs (Chen et al. 2020; D. Li et al. 2020) and environmental matrices (Wan et al. 2019; Wan et al. 2020; Wang et al. 2019; Zhang et al. 2021a). In addition, NEOs were easily metabolized through phase I metabolic biotransformation in mammal (Casida 2011; Ford and Casida 2006a, b). This might be the reason for the high m-NEO concentrations found in blood samples from both populations. Interestingly, the median blood concentrations of $\Sigma \mathrm{NEO} / \mathrm{IMI}$ eq in the liver cancer population $(23.0 / 44.4 \mathrm{ng} / \mathrm{mL})$ were significantly higher $(p<0.05)$ than those in the healthy population $(7.75 / 23.9 \mathrm{ng} / \mathrm{mL}$; Table 1). Furthermore, the median level of $\Sigma \mathrm{m}-\mathrm{NEOs}$ in the liver cancer population (12.3 ng/mL) was approximately fourfold higher than that in the healthy population $(3.69 \mathrm{ng} / \mathrm{mL}$; Table 1$)$. Our findings indicated that the liver cancer population was highly exposed to NEOs and their metabolites.

Limited studies have reported the concentrations of NEOs and their metabolites in blood samples (Fuke et al. 2014; Proença et al. 2005; Xu et al. 2021; Yeter and Aydın 2014). The median blood concentrations of NEOs and their metabolites in the liver cancer population in this study were at least onefold higher than those reported in South China (Table 2) (Xu et al. 2021). Moreover, the median levels of most NEOs and their metabolites (except for IMI and UF) in blood samples collected from the healthy population were considerably higher than those reported by Xu et al. (2021) (Table 2). With the comparison of previous studies reported on serum samples, the median blood concentrations of ACE $(0.49 \mathrm{and} 0.29 \mathrm{ng} / \mathrm{mL}), \mathrm{THI}(0.21$ and 0.29 $\mathrm{ng} / \mathrm{mL})$, and THIX $(0.20$ and $0.19 \mathrm{ng} / \mathrm{mL})$ in this study are relatively higher than those reported in South China (ACE: $0.04 \mathrm{and} 0.05 \mathrm{ng} / \mathrm{mL}$; THI: 0.06 and $0.01 \mathrm{ng} / \mathrm{mL}$; THIX: 0.16 and $0.16 \mathrm{ng} / \mathrm{mL}$ ) (Zhang et al., 2021), East China (ACE: $<0.005 \mathrm{ng} / \mathrm{mL} ; \mathrm{THI}:<0.018 \mathrm{ng} / \mathrm{mL}$; THIX: $<0.023 \mathrm{ng} / \mathrm{mL})(\mathrm{Chen}$ et al. 2021), and Saudi Arabia (ACE: $<0.002 \mathrm{ng} / \mathrm{mL}$; THI: not detected; THIX: < $0.061 \mathrm{ng} / \mathrm{mL}$; Table 2) (Li et al. 2020a). However, the median blood levels of UF (1.88 and $0.73 \mathrm{ng} / \mathrm{mL}$ ) and Of-IMI (2.03 and $1.28 \mathrm{ng} / \mathrm{mL})$ were comparable to those reported in South China (UF: $1.27 \mathrm{and} 0.73 \mathrm{ng} / \mathrm{mL}$; Of-IMI: 3.08 and $1.41 \mathrm{ng} / \mathrm{mL})$, but the median concentration of ACE-dm (1.61 and $0.79 \mathrm{ng} / \mathrm{mL}$ ) was significantly lower (5.99 and $2.02 \mathrm{ng} / \mathrm{mL}$; Table 2) (Zhang et al. 2021c). These differences might be explained by the different sample size, NEO usage pattern, human bodily fluids, such as blood and serum, and populations. 
Table 2

Summary of median concentration $(\mathrm{ng} / \mathrm{mL})$ of NEOs and their metabolites in blood samples from this study with those reported for other countries.

\begin{tabular}{|c|c|c|c|c|c|c|c|c|c|c|c|c|c|c|c|}
\hline countries & $\begin{array}{l}\text { sampling } \\
\text { date }\end{array}$ & age & $\mathrm{n}^{a}$ & ACE & CLO & DIN & IMI & THI & THIX & DN & UF & $\begin{array}{l}\text { ACE- } \\
\text { dm }\end{array}$ & $\begin{array}{l}\text { 5- } \\
\text { OH- } \\
\text { IMI }\end{array}$ & $\begin{array}{l}\text { Of- } \\
\text { IMI }\end{array}$ & references \\
\hline China & $\begin{array}{l}2018- \\
2019\end{array}$ & $\begin{array}{l}11- \\
88\end{array}$ & 274 & 0.49 & 0.47 & 0.69 & 0.56 & 0.21 & 0.20 & 0.87 & 1.88 & 1.61 & 0.79 & 2.03 & This study \\
\hline China & $\begin{array}{l}2018- \\
2019\end{array}$ & $\begin{array}{l}22- \\
91\end{array}$ & 100 & 0.29 & 0.31 & 0.62 & 0.21 & 0.29 & 0.19 & 0.24 & 0.73 & 0.79 & 0.36 & 1.28 & This study \\
\hline China & 2018 & $\begin{array}{l}20- \\
27\end{array}$ & 196 & 0.13 & 0.22 & 0.12 & 0.29 & 0.08 & 0.08 & $\begin{array}{l}\mathrm{NR} \\
b\end{array}$ & 0.8 & 0.58 & NR & 0.78 & $\begin{array}{l}\text { (Xu et al., } \\
2021)\end{array}$ \\
\hline China $^{d}$ & 2019 & $\begin{array}{l}52- \\
89\end{array}$ & 120 & 0.04 & 1.40 & 0.68 & 1.00 & 0.06 & 0.16 & NR & 1.27 & 5.99 & NR & 3.08 & $\begin{array}{l}\text { (Zhang et } \\
\text { al., 2021) }\end{array}$ \\
\hline China $^{d}$ & 2019 & $\begin{array}{l}50- \\
89\end{array}$ & 80 & 0.05 & 0.71 & 0.24 & 0.76 & 0.01 & 0.16 & NR & 0.73 & 2.02 & NR & 1.41 & $\begin{array}{l}\text { (Zhang et } \\
\text { al., 2021) }\end{array}$ \\
\hline China $^{d}$ & $\mathrm{NA}^{c}$ & $\begin{array}{l}9- \\
80\end{array}$ & 120 & $\begin{array}{l}< \\
0.005\end{array}$ & $<.016$ & $\begin{array}{l}< \\
0.035\end{array}$ & $<0.018$ & $\begin{array}{l}< \\
0.006\end{array}$ & $<.023$ & NR & NR & NR & NR & NR & $\begin{array}{l}\text { (Chen et } \\
\text { al., 2021) }\end{array}$ \\
\hline $\begin{array}{l}\text { Saudi } \\
\text { Arabia }^{d}\end{array}$ & 2017 & $\begin{array}{l}41- \\
78\end{array}$ & 25 & $\begin{array}{l}< \\
0.002\end{array}$ & $<.025$ & $\dot{0} 035$ & 0.04 & $\mathrm{ND}^{e}$ & $\begin{array}{l}< \\
0.061\end{array}$ & NR & NR & 0.03 & NR & NR & $\begin{array}{l}\text { (Li et al., } \\
2020)\end{array}$ \\
\hline Turkey & NA & $\begin{array}{l}7- \\
29\end{array}$ & 3 & 2700 & NR & NR & NR & NR & NR & NR & NR & NR & NR & NR & $\begin{array}{l}\text { (Yeter and } \\
\text { Aydın, } \\
2014 \text { ) }\end{array}$ \\
\hline Japan & NA & 70 & 1 & NR & NR & NR & 105,000 & NR & NR & NR & NR & NR & NR & NR & $\begin{array}{l}\text { (Fuke et } \\
\text { al., 2014) }\end{array}$ \\
\hline $\begin{array}{l}\text { Sri } \\
\text { Lanka }\end{array}$ & $\begin{array}{l}2002- \\
2007\end{array}$ & $<14$ & 68 & NR & NR & NR & 10.6 & NR & NR & NR & NR & NR & NR & NR & $\begin{array}{l}\text { (Mohamed } \\
\text { et al., } \\
2009 \text { ) }\end{array}$ \\
\hline Portugal & NA & $\begin{array}{l}33- \\
66\end{array}$ & 2 & NR & NR & NR & $7280^{g}$ & NR & NR & NR & NR & NR & NR & NR & $\begin{array}{l}\text { (Proença } \\
\text { et al., } \\
2005 \text { ) }\end{array}$ \\
\hline
\end{tabular}

\subsection{Correlations and source analysis}

Associations among the concentrations (log-transformed) of individual p-NEO, m-NEOs, and between m-NEOs and their corresponding p-NEOs in blood samples were examined through Pearson correlation analysis, and all sampling populations were considered collectively (Fig. 2).

In general, significant positive relationships $(p<0.01)$ were found among most p-NEO concentrations in the blood, and the correlation coefficients ranged from 0.213 (IMI vs. THIX) to 0.459 (IMI vs. THI; Fig. 2). Our findings were similar to those of previous studies, which suggested significant positive correlations among the concentrations of individual p-NEOs in urine (Zhang et al. 2019), saliva and periodontal blood (Zhang et al. 2021b), and tooth (N. Zhang et al. 2021) samples. NEOs were commonly detected in foodstuffs (Chen et al. 2020; D. Li et al. 2020; Lu et al. 2018; Song et al. 2018) and environmental matrices (i.e., water and indoor dust) (Mahai et al. 2021; Wan et al. 2019; Wang et al. 2019; Zhang et al. 2021a) in China. Thus, these results suggest that the sources of these p-NEOs are common or related.

Importantly, the relationships between p-NEOs (i.e., ACE, DIN, and IMI) and their corresponding m-NEOs (i.e., ACE-dm, DN, UF, 5-OH-IMI, and Of-IMI) were positively correlated $(p<0.05)$, with correlation coefficients ranging from 0.173 (DIN vs. DN) to 0.338 (DIN vs. UF; Fig. 2). Our results were consistent with those of the previous reports on urinary (Song et al. 2020; Zhang et al. 2021a) and blood (Xu et al. 2021) concentrations. As mentioned above, pNEOs could be easily metabolized into characteristic metabolites through phase I reaction in mammals (Casida 2011; Ford and Casida 2006a, b). The significant positive relationships between $\mathrm{p}-\mathrm{NEO}$ and $\mathrm{m}$-NEOs might result from the metabolic transformation of $\mathrm{p}$-NEOs in humans. However, $\mathrm{m}$-NEOs could be directly detected in water, dust, soil, tea, fruits, and vegetable samples from China (Chen et al. 2020; S. Li et al. 2020; Li et al. 2020; Mahai et al. 2021; Wan et al. 2019; Wan et al. 2020; Zhang et al. 2020; Zhang et al. 2021a), which indicated that exogenous m-NEOs might be an important source of dietary m-NEO exposure. Furthermore, significant positive correlations were found between ACE-dm and 5-OH-IMI $(r=0.273, p<0.01)$, ACE-dm and $\mathrm{DN}(r=0.182, p<0.05)$, ACE-dm and UF ( $r=0.335, p<0.01), 5-\mathrm{OH}-\mathrm{IMI}$ and DN $(r=0.298, p<0.01), 5-\mathrm{OH}-\mathrm{IMI}$ and UF $(r=0.271, p<0.01)$, and Of-IMI and DN $(r=0.593, p<0.01$; Fig. 2). Therefore, the sources of $\mathrm{m}$-NEOs might be not only be from the metabolic biotransformation of $\mathrm{p}-\mathrm{NEO}$ in the human body but also from exogenous sources.

3.3 Association of blood levels with demographic factors

Page 6/16 
In the present study, age-related patterns of the levels of NEOs and their metabolites in all donors were examined using Pearson's rank correlation. No significant correlations $(p>0.05)$ were found between age and concentrations of target analytes. We further categorized the age into three groups, on the basis of age histogram (Figure S1): $<40$ years, 40-60 years, and $>60$ years. No significant differences $(p>0.05$, Mann-Whitney $\mathrm{U}$ test) in blood NEOs and their metabolites concentrations were found among these three age groups both in health and liver cancer populations (Fig. 3). A similar pattern was also found in previous reports on the levels of NEOs and their metabolites in human urine, saliva, periodontal blood, tooth, and blood samples collected from China (Song et al. 2020; Xu et al. 2021; Zhang et al. 2019; Zhang et al. 2021b; N. Zhang et al. 2021). These results indicate that human exposure to NEOs and their metabolites might not relatively differ in these populations.

Subsequently, gender-related differences in the levels of NEOs and their metabolites among health and liver cancer populations were examined. In the healthy population, the median concentrations of most target analytes (except for ACE, IMI, 5-OH-IMI, and ACE-dm) in females were higher than those in males (Fig. 3a). Moreover, significant differences $(p<0.05)$ in the median concentrations ( $\mathrm{ng} / \mathrm{mL})$ of CLO (0.39 vs. 0.23$)$, THI (0.46 vs. 0.26$)$, DIN (0.76 vs. 0.50$)$, UF (0.98 vs. 0.48$)$, and $\mathrm{IMI}_{\text {eq }}$ ( 28.8 vs. 20.7) were observed between females and males (Fig. 3a). Similarly, females from the liver cancer population had higher median levels of most NEOs and their metabolites (except for ACE, IMI, THIX, DN, and ACE-dm) than males (Fig. 3b). However, no gender-related differences were found in liver cancer population (Fig. 3b). Such trend was also found in previous studies reported in human matrices (i.e., urine, saliva, periodontal blood, tooth, and blood), which indicated that females had higher concentrations of NEOs and their metabolites than males (Ospina et al. 2019; Song et al. 2020; Tao et al. 2019; Xu et al. 2021; Zhang et al. 2021a, b, c; N. Zhang et al. 2021). Although the mechanism of gender-related pattern is still unclear, the reason might be that females have smaller body sizes, higher metabolic capability, and higher consumption of foodstuffs than males (Chen et al. 2020; Steer et al. 2006; Tipton 2001).

\subsection{Association of blood levels of NEOs and their metabolites with liver cancer}

The associations between NEOs and their metabolites concentrations and liver cancer were examined. The crude and adjusted ORs for liver cancer diagnosis and $95 \% \mathrm{Cls}$ for target analytes in blood samples were presented in Table 3. In addition, the correlations between exposure to these target compounds and a-fetoprotein (AFP) values, a biomarker commonly used in the management of population with liver cancer (Giannini et al. 2014), were analyzed (Table S 5).

Table 3

Odds of liver cancer diagnosis by blood concentrations of NEOs and their metabolites presented in a liver cancer population $(n=274)$-health population $(n=100)$ study from South China.

\begin{tabular}{|lllll|}
\hline Compounds $(\mathrm{ng} / \mathrm{mL})$ & Crude & $p$-trend & Adjusted ${ }^{a}$ & $p$-trend \\
\hline ACE & ORs $(95 \% \mathrm{Cl})$ & & ORs $(95 \% \mathrm{Cl})$ & \\
\hline ACE-dm & $0.42(0.12-1.13)$ & $>0.05$ & $0.31(0.09-0.98)$ & $>0.05$ \\
\hline DIN & $3.45(0.36-7.13)$ & $<0.01$ & $3.02(0.22-6.65)$ & $<0.05$ \\
\hline DN & $0.78(0.16-1.88)$ & $>0.05$ & $0.43(0.10-1.58)$ & $>0.05$ \\
\hline UF & $2.33(0.31-4.20)$ & $<0.05$ & $2.25(0.25-3.02)$ & $>0.05$ \\
\hline THI & $2.64(0.47-4.33)$ & $<0.05$ & $2.31(0.13-4.15)$ & $>0.05$ \\
\hline CLO & $0.72(0.24-2.88)$ & $>0.05$ & $0.48(0.13-2.05)$ & $>0.05$ \\
\hline THIX & $1.88(0.76-3.77)$ & $>0.05$ & $1.27(0.44-2.83)$ & $>0.05$ \\
\hline IMI & $0.99(0.31-2.75)$ & $>0.05$ & $0.63(0.24-1.96)$ & $>0.05$ \\
\hline Of-IMI & $2.24(0.75-5.86)$ & $>0.05$ & $1.66(0.47-4.37)$ & $>0.05$ \\
\hline 5-OH-IMI & $3.31(1.68-8.56)$ & $<0.05$ & $2.53(1.01-6.09)$ & $>0.05$ \\
\hline Ip-NEOs & $2.55(0.52-5.54)$ & $<0.05$ & $2.26(0.41-5.07)$ & $>0.05$ \\
\hline Im-NEOs & $5.71(3.14-12.8)$ & $>0.05$ & $4.89(2.89-10.8)$ & $>0.05$ \\
\hline INEOs & $8.93(4.37-19.0)$ & $<0.01$ & $7.58(3.72-16.5)$ & $<0.05$ \\
\hline IMleq & $8.67(3.02-18.6)$ & $<0.01$ & $6.24(2.83-13.7)$ & $<0.05$ \\
\hline a Adjusted for age and gender. & $9.02(5.77-22.7)$ & $<0.01$ & $7.63(3.99-17.9)$ & $<0.05$ \\
\hline
\end{tabular}

As shown in Table 1, the median concentrations of target analytes (except for THI) in blood samples collected from the liver cancer population were higher than those from the healthy population. In addition, significant liver cancer-related differences $(p<0.05)$ were found in the blood levels of ACE, IMI, 5-OH-IMI, Of-IMI, ACE-dm, DN, UF, $\Sigma \mathrm{m}-\mathrm{NEO}$, $\Sigma \mathrm{NEOs,} \mathrm{and} \mathrm{IMI} \mathrm{eq} \mathrm{(Fig.} \mathrm{5).} \mathrm{Furthermore,} \mathrm{the} \mathrm{associations} \mathrm{between} \mathrm{blood} \mathrm{concentrations} \mathrm{of} \mathrm{5-OH-IMI} \mathrm{(OR}$ $=2.55,95 \% \mathrm{Cl}=0.52-5.54, p<0.05)$, Of-IMI (OR = 3.31, 95\% Cl=1.68-8.56, $p<0.05)$, ACE-dm $(\mathrm{OR}=3.45,95 \% \mathrm{Cl}=0.36-7.13, p<0.01), \mathrm{DN}(\mathrm{OR}=2.33$, 
$95 \% \mathrm{Cl}=0.31-4.20, p<0.05), \mathrm{UF}(\mathrm{OR}=2.64,95 \% \mathrm{Cl}=0.47-4.33, p<0.05), \Sigma \mathrm{m}-\mathrm{NEO}$ ( $\mathrm{OR}=8.93,95 \% \mathrm{Cl}=4.37-19.0, p<0.01), \Sigma \mathrm{NEO}(\mathrm{OR}=8.67,95 \% \mathrm{Cl}$ $=3.02-18.6, p<0.01)$, and $\mathrm{IMI}_{\mathrm{eq}}(\mathrm{OR}=9.02,95 \% \mathrm{Cl}=5.77-22.7, p<0.01)$ and liver cancer were significant (Table 3). After the multivariate analyses were adjusted by age and gender, associations between blood levels of ACE-dm (adjusted OR $=3.02,95 \% \mathrm{Cl}=0.22-6.65, p<0.05$ ), $\Sigma \mathrm{m}-\mathrm{NEO}$ s (adjusted $\mathrm{OR}=7.58,95 \% \mathrm{Cl}=3.72-16.5, p<0.05)$, $\Sigma$ NEOs (adjusted OR $=6.42,95 \% \mathrm{Cl}=2.83-13.7, p<0.05)$, and IMI eq (adjusted OR = 7.63, 95\% Cl=3.99-17.9, $p$ $<0.05)$ and liver cancer still showed statistical significance (Table 3). Meanwhile, the AFP values and blood concentrations of ACE-dm ( $r=0.453, p<$

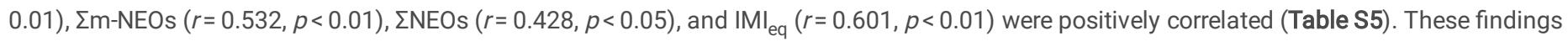
indicated that human exposure to NEOs and their metabolites was associated with liver cancer, and the blood levels of NEOs and their metabolites were correlated with increased odds of liver cancer prevalence in this population from China. Our results were similar to recent reports, which showed that human exposure to NEOs and their metabolites would increase the odds of disease prevalence (i.e., osteoporosis and periodontitis) (Li et al. 2020a; N. Zhang et al. 2021; Zhang et al. 2021c).

The metabolism and elimination of pollutants are conducted in the liver. In addition, the liver is a critical target organ that is damaged by NEOs (Han et al. 2018). Previous studies reported that NEOs and their metabolites could cause hepatoxicity effect on zebrafish birds, rabbits, mice, and even human beings (Alarcan et al. 2020; Arfat et al. 2014; Chang et al. 2020; El Okle et al. 2018; Emam et al. 2018; Green et al. 2005a,b; Swenson and Casida 2013). Furthermore, several animal reports demonstrated that NEOs could penetrate the organ (i.e., liver) through the production of reactive oxygen species, causing remarkable oxidative damage (El Okle et al. 2018; Iturburu et al. 2018; Vieira et al. 2018; Wang et al. 2018). In addition, more recent studies have shown a positive correlation between NEO exposure and oxidative stress in humans (Li et al. 2020b; Zhang et al. 2021b). As mentioned above, the toxicity of m-NEOs was higher than that of their corresponding p-NEOs (Casida 2011; Honda et al. 2006; Marfo et al. 2015; Suchail et al. 2001; Suchail et al. 2003; Zhang et al. 2021b). This might explain the relationships between the blood levels of NEOs and their metabolites (especially for m-NEOs) and liver cancer. However, given that other pollutants could also cause liver cancer (Parrón et al. 2014; Vopham et al. 2017; Yueh et al. 2015), coexposure assessment is needed in future studies.

\section{Conclusions}

NEOs and their metabolites were widely detected (61-94\%, Table 1) in blood samples collected from healthy $(n=100)$ and liver cancer $(n=274)$ populations in China. The median blood concentrations of NEOs and their metabolites ranged within 0.19 to $1.28 \mathrm{ng} / \mathrm{mL}$ for the healthy population and 0.20 to $2.03 \mathrm{ng} / \mathrm{mL}$ for the liver cancer population (Table 1). These findings indicated that human exposure to NEOs and their metabolites was widespread in healthy and liver cancer populations in China. Of-IMI was the predominant NEO in blood samples, accounting for $24.1 \%$ and $20.7 \%$ for healthy and liver cancer populations, respectively. The associations among most p-NEOs were positively correlated $(p<0.05$, Fig. 2$)$. This result suggested that the sources of $\mathrm{p}$-NEOs were related or common. In addition, significant positive relationships $(p<0.05$, Fig. 2$)$ were observed among mNEOs; furthermore, significant positive relationships ( $p<0.05$, Fig. 2$)$ were found between m-NEO and their corresponding $p$-NEOs. Our data showed that m-NEOs were not only from endogenous sources, but also from exogenous sources. Although gender-related differences were only found in the healthy population, females had higher median concentrations of most NEOs and their metabolites than males both in the healthy and liver cancer populations (Fig. 4). Furthermore, significant positive correlations between NEO exposure and liver cancer were found (Table 3), which revealed that NEOs concentrations were associated with increased odds of liver cancer prevalence. To our knowledge, this study is the first work to report the concentrations of 5-OH-IMI and DN in blood samples, and examine the associations between NEO concentrations and liver cancer.

\section{Declarations}

\section{Conflict of interest}

The authors declare that they have no conflict of interest.

\section{Acknowledgements}

This study was supported by grants from the National Natural Science Foundation of China (No. 31970862), the "111" project (No. B16021). Grants from China Postdoctoral Science Foundation: 2020M673045. We gratefully acknowledge the donors who contributed the blood samples for this study.

\section{References}

1. Alarcan J, Waizenegger J, Solano MDLM, Lichtenstein D, Luckert C, Peijnenburg A, Stoopen G, Sharma RP, Kumar V, Marx-Stoelting P, et al. (2020) Hepatotoxicity of the pesticides imazalil, thiacloprid and clothianidin - Individual and mixture effects in a 28-day study in female Wistar rats. Food Chem Toxicol 140:111306 10.1016/j.fct.2020.111306

2. Arfat Y, Mahmood N, Tahir MU, Rashid M, Anjum S, Zhao F, Li D, Sun Y, Hu L, Zhihao C, et al. (2014) Effect of imidacloprid on hepatotoxicity and nephrotoxicity in male albino mice. Toxicology Reports 1:554-561 10.1016/j.toxrep.2014.08.004

3. Casida JE (2011) Neonicotinoid Metabolism: Compounds, Substituents, Pathways, Enzymes, Organisms, and Relevance. J Agr Food Chem 59:2923-2931 
4. Chang Y, Mao L, Zhang L, Zhang Y, Jiang H (2020) Combined toxicity of imidacloprid, acetochlor, and tebuconazole to zebrafish (Danio rerio): acute toxicity and hepatotoxicity assessment. Environ Sci Pollut R 27(10):10286-10295 10.1007/s11356-020-07653-3

5. Chen D, Zhang Y, Lv B, Liu Z, Han J, Li J, Zhao Y, Wu Y (2020) Dietary exposure to neonicotinoid insecticides and health risks in the Chinese general population through two consecutive total diet studies. Environ Int 135:105399 10.1016/j.envint.2019.105399

6. Chen JG, Zhang SW (2011) Liver cancer epidemic in China: Past, present and future. Semin Cancer Biol 21(1):59-69

10.1016/j.semcancer.2010.11.002

7. Chen Q, Zhang Y, Li J, Su G, Chen Q, Ding Z, Sun H (2021) Serum concentrations of neonicotinoids, and their associations with lipid molecules of the general residents in Wuxi City, Eastern China. J Hazard Mater 413:125235 10.1016/j.jhazmat.2021.125235

8. Cimino AM, Boyles AL, Thayer KA, Perry MJ (2017) Effects of Neonicotinoid Pesticide Exposure on Human Health: A Systematic Review. Environ Health Persp 125(2):155-162 10.1289/EHP515

9. Cocco P, Kazerouni N, Zahm SH (2000) Cancer mortality and environmental exposure to DDE in the United States. Environ Health Perspect 108(1):1-4 10.1289/ehp.001081

10. de Brito Sa Stoppelli I, Crestana S (2005) Pesticide exposure and cancer among rural workers from Bariri, São Paulo State, Brazil. Environ Int 31(5):731-738 10.1016/j.envint.2005.02.002

11. El Okle OS, El Euony OI, Khafaga AF, Lebda MA (2018) Thiamethoxam induced hepatotoxicity and pro-carcinogenicity in rabbits via motivation of oxidative stress, inflammation, and anti-apoptotic pathway. Environ Sci Pollut R 25(5):4678-4689 10.1007/s11356-017-0850-0

12. Emam H, Ahmed E, Abdel-Daim M (2018) Antioxidant capacity of omega-3-fatty acids and vitamin E against imidacloprid-induced hepatotoxicity in Japanese quails. Environ Sci Pollut R 25(12):11694-11702 10.1007/s11356-018-1481-9

13. Ford KA, Casida JE (2006a) Chloropyridinyl Neonicotinoid Insecticides: Diverse Molecular Substituents Contribute to Facile Metabolism in Mice. Chem Res Toxicol 19(7):944-951 10.1021/tx0600696

14. Ford KA, Casida JE (2006b) Unique and Common Metabolites of Thiamethoxam, Clothianidin, and Dinotefuran in Mice. Chem Res Toxicol 19(11):1549-1556 10.1021/tx0601859

15. Franka SD, Tooker JF (2020) Neonicotinoids pose undocumented threats to food webs. PNAS 117:22609-22613

16. Fu J, Wang H (2018) Precision diagnosis and treatment of liver cancer in China. Cancer Lett 412:283-288 10.1016/j.canlet.2017.10.008

17. Fuke C, Nagai T, Ninomiya K, Fukasawa M, Ihama Y, Miyazaki T (2014) Detection of imidacloprid in biological fluids in a case of fatal insecticide intoxication. Legal Med-Tokyo 16(1):40-43 10.1016/j.legalmed.2013.10.007

18. Giannini EG, Sammito G, Farinati F, Ciccarese F, Pecorelli A, Rapaccini GL, Di Marco M, Caturelli E, Zoli M, Borzio F, et al. (2014) Determinants of alpha-fetoprotein levels in patients with hepatocellular carcinoma: Implications for its clinical use. Cancer-Am Cancer Soc 120(14):2150-2157 10.1002/cncr.28706

19. Green T, Toghill A, Lee R, Waechter F, Weber E, Noakes J (2005a) Thiamethoxam Induced Mouse Liver Tumors and Their Relevance to Humans. Toxicol Sci 86(1):36-47 10.1093/toxsci/kfi124

20. Green T, Toghill A, Lee R, Waechter F, Weber E, Peffer R, Noakes J, Robinson M (2005b) Thiamethoxam Induced Mouse Liver Tumors and Their Relevance to Humans. Toxicol Sci 86(1):48-55 10.1093/toxsci/kfi125

21. Han W, Tian Y, Shen X (2018) Human exposure to neonicotinoid insecticides and the evaluation of their potential toxicity: An overview. Chemosphere 192:59-65 10.1016/j.chemosphere.2017.10.149

22. Hazarika M, Hazarika R (2013) Pesticide Exposure and Cancers in Barpeta District, Assam - A Case for Control Study. Nature environment and pollution technology 12(3):467

23. Honda H, Tomizawa M, Casida JE (2006) Insect nicotinic Acetylcholine Receptors: Neonicotinoid Binding Site Specificity Is Usually but Not Always Conserved with Varied Substituents and Species. J Agr Food Chem 54:3365-3371

24. Hu R, Huang X, Huang J, Li Y, Zhang C, Yin Y, Chen Z, Jin Y, Cai J, Cui F (2015) Long- and Short-Term Health Effects of Pesticide Exposure: A Cohort Study from China. Plos One 10(6):e128766 10.1371/journal.pone.0128766

25. Iturburu FG, Simoniello MF, Medici S, Panzeri AM, Menone ML (2018) Imidacloprid Causes DNA Damage in Fish: Clastogenesis as a Mechanism of Genotoxicity. B Environ Contam Tox 100(6):760-764 10.1007/s00128-018-2338-0

26. Jaga K, Dharmani C (2005) The Epidemiology of Pesticide Exposure and Cancer: A Review. Rev Environ Health 20(1) 10.1515/REVEH.2005.20.1.15

27. Li AJ, Banjabi AA, Takazawa M, Kumosani TA, Yousef JM, Kannan K (2020a) Serum concentrations of pesticides including organophosphates, pyrethroids and neonicotinoids in a population with osteoarthritis in Saudi Arabia. Sci Total Environ 737:139706 10.1016/j.scitotenv.2020.139706

28. Li AJ, Martinez-Moral M, Kannan K (2020b) Variability in urinary neonicotinoid concentrations in single-spot and first-morning void and its association with oxidative stress markers. Environ Int 135:105415 10.1016/j.envint.2019.105415

29. Li D, Zhang H, Chang M, Shen K, Zhang N, Zhu K, Zhou Z, Zhang W, Wang Q, Liu X, et al. (2020) Neonicotinoid insecticide and their metabolite residues in fruit juices: Implications for dietary intake in China. Chemosphere 261:127682 10.1016/j.chemosphere.2020.127682

30. Li S, Ren J, Li L, Chen R, Li J, Zhao Y, Chen D, Wu Y (2020) Temporal variation analysis and risk assessment of neonicotinoid residues from tea in China. Environ Pollut 266:115119 10.1016/j.envpol.2020.115119

Page 9/16 
31. Lu C, Chang C, Palmer C, Zhao M, Zhang Q (2018) Neonicotinoid Residues in Fruits and Vegetables: An Integrated Dietary Exposure Assessment Approach. Environ Sci Technol 52(5):3175-3184 10.1021/acs.est.7b05596

32. Lu C, Lu Z, Lin S, Dai W, Zhang Q (2020) Neonicotinoid insecticides in the drinking water system - Fate, transportation, and their contributions to the overall dietary risks. Environ Pollut 258:113722 10.1016/j.envpol.2019.113722

33. Mahai G, Wan Y, Xia W, Wang A, Shi L, Qian X, He Z, Xu S (2021) A nationwide study of occurrence and exposure assessment of neonicotinoid insecticides and their metabolites in drinking water of China. Water Res 189:116630 10.1016/j.watres.2020.116630

34. Marfo JT, Fujioka K, Ikenaka Y, Nakayama SMM, Mizukawa H, Aoyama Y, Ishizuka M, Tair K (2015) Relationship between Urinary NDesmethylAcetamiprid and Typical Symptoms including Neurological Findings: A Prevalence CaseControl Study. Plos One 10:e142172

35. Mohamed F, Gawarammana I, Robertson TA, Roberts MS, Palangasinghe C, Zawahir S, Jayamanne S, Kandasamy J, Eddleston M, Buckley NA, et al. (2009) Acute human self-poisoning with imidacloprid compound: a neonicotinoid insecticide. Plos One 4(4):e5127 10.1371/journal.pone.0005127

36. Osaka A, Ueyama J, Kondo T, Nomura H, Sugiura Y, Saito I, Nakane K, Takaishi A, Ogi H, Wakusawa S, et al. (2016) Exposure characterization of three major insecticide lines in urine of young children in Japan-neonicotinoids, organophosphates, and pyrethroids. Environ Res 147:89-96 10.1016/j.envres.2016.01.028

37. Ospina M, Wong L, Baker SE, Serafim AB, Morales-Agudelo P, Calafat AM (2019) Exposure to neonicotinoid insecticides in the U.S. general population: Data from the 2015-2016 national health and nutrition examination survey. Environ Res 176:108555 10.1016/j.envres.2019.108555

38. Parrón T, Requena M, Hernández AF, Alarcón R (2014) Environmental exposure to pesticides and cancer risk in multiple human organ systems. Toxicol Lett 230(2):157-165 10.1016/j.toxlet.2013.11.009

39. Proença P, Teixeira H, Castanheira F, Pinheiro J, Monsanto PV, Marques EP, Vieira DN (2005) Two fatal intoxication cases with imidacloprid: LC/MS analysis. Forensic Sci Int 153(1):75-80 10.1016/j.forsciint.2005.04.015

40. Simon-Delso N, Amaral-Rogers V, Belzunces LP, Bonmatin JM, Chagnon M, Downs C, Furlan L, Gibbons DW, Giorio C, Girolami V, et al. (2015) Systemic insecticides (neonicotinoids and fipronil): trends, uses, mode of action and metabolites. Environ Sci Pollut Res Int 22(1):5-34 10.1007/s11356-014-3470-y

41. Song S, Zhang C, Chen Z, He F, Wei J, Tan H, Li X (2018) Simultaneous determination of neonicotinoid insecticides and insect growth regulators residues in honey using LC-MS/MS with anion exchanger-disposable pipette extraction. J Chromatogr a 1557:51-61 10.1016/j.chroma.2018.05.003

42. Song S, Zhang T, Huang Y, Zhang B, Guo Y, He Y, Huang X, Bai X, Kannan K (2020) Urinary metabolites of neonicotinoid insecticides: Levels and recommendations for future biomonitoring studies in China. Environ Sci Technol 54:8210-8220

43. Steer CD, Grey CNB, Alspac ST, The AST (2006) Socio-demographic characteristics of UK families using pesticides and weed-killers. J Expo Sci Env Epid 16(3):251-263 10.1038/sj.jea.7500455

44. Suchail S, Debrauwer L, Belzunces LP (2003) Metabolism of imidacloprid in Apis mellifera. Pest Manag Sci 60:291-296

45. Suchail SV, Guez D, Belzunces LP (2001) Discrepancy between acute and chronic toxicity induced by imidacloprid and ith metabolites in apis mellifera. Environ Toxicol Chem 20:2482-2486

46. Swenson TL, Casida JE (2013) Neonicotinoid formaldehyde generators: Possible mechanism of mouse-specific hepatotoxicity/hepatocarcinogenicity of thiamethoxam. Toxicol Lett 216(2-3):139-145 10.1016/j.toxlet.2012.11.027

47. Tao Y, Dong F, Xu J, Phung D, Liu Q, Li R, Liu X, Wu X, He M, Zheng Y (2019) Characteristics of neonicotinoid imidacloprid in urine following exposure of humans to orchards in China. Environ Int 132:105079 10.1016/j.envint.2019.105079

48. Tipton KD (2001) Gender differences in protein metabolism. Curr Opin Clin Nutr 4:493-498 https://doi.org/10.1016/j.semss.2020.100826

49. Tomizawa M, Casida JE (2005) Neonicotinoid insecticide toxicology: Mechanisms of selective action. Annu Rev Pharmacol 45(1):247-268 10.1146/annurev.pharmtox.45.120403.095930

50. Ueyama J, Harada KH, Koizumi A, Sugiura Y, Kondo T, Saito I, Kamijima M (2015) Temporal Levels of Urinary Neonicotinoid and Dialkylphosphate Concentrations in Japanese Women Between 1994 and 2011. Environ Sci Technol 49(24):14522-14528 10.1021/acs.est.5b03062

51. Vieira CED, Pérez MR, Acayaba RD, Raimundo CCM, Dos Reis Martinez CB (2018) DNA damage and oxidative stress induced by imidacloprid exposure in different tissues of the Neotropical fish Prochilodus lineatus. Chemosphere 195:125-134 10.1016/j.chemosphere.2017.12.077

52. VoPham T, Bertrand KA, Hart JE, Laden F, Brooks MM, Yuan J, Talbott EO, Ruddell D, Chang CH, Weissfeld JL (2017) Pesticide exposure and liver cancer: a review. Cancer Cause Control 28(3):177-190 10.1007/s10552-017-0854-6

53. Wan Y, Han Q, Wang Y, He Z (2020) Five degradates of imidacloprid in source water, treated water, and tap water in Wuhan, central China. Sci Total Environ 741:140227 10.1016/j.scitotenv.2020.140227

54. Wan Y, Wang Y, Xia W, He Z, Xu S (2019) Neonicotinoids in raw, finished, and tap water from Wuhan, Central China: Assessment of human exposure potential. Sci Total Environ 675:513-519 10.1016/j.scitotenv.2019.04.267

55. Wang A, Mahai G, Wan Y, Jiang Y, Meng Q, Xia W, He Z, Xu S (2019) Neonicotinoids and carbendazim in indoor dust from three cities in China: Spatial and temporal variations. Sci Total Environ 695:133790 10.1016/j.scitotenv.2019.133790 
56. Wang A, Mahai G, Wan Y, Yang Z, He Z, Xu S, Xia W (2020) Assessment of imidacloprid related exposure using imidacloprid-olefin and desnitroimidacloprid: Neonicotinoid insecticides in human urine in Wuhan, China. Environ Int 141:105785 10.1016/j.envint.2020.105785

57. Wang X, Anadon A, Wu Q, Qiao F, Ares I, Martinez-Larranaga MR, Yuan Z, Martinez MA (2018) Mechanism of Neonicotinoid Toxicity: Impact on Oxidative Stress and Metabolism. Annu Rev Pharmacol Toxicol 58:471-507 10.1146/annurev-pharmtox-010617-052429

58. Xu M, Zhang Z, Li Z, Kan S, Liu Z, Wang D, Liu Q, Zhang H (2021) Profiles of neonicotinoid insecticides and characteristic metabolites in paired urine and blood samples: Partitioning between urine and blood and implications for human exposure. Sci Total Environ 773:145582 10.1016/j.scitotenv.2021.145582

59. Yeter O, Aydın A (2014) Determination of Acetamiprid and IM-1-2 in PostMortem Human Blood, Liver, Stomach Contents by HPLC-DAD. J Forensic Sci 59(1):287-292 10.1111/1556-4029.12368

60. Yueh M, Taniguchi K, Chen S, Evans RM, Hammock BD, Karin M, Tukey ARH (2015) The commonly used antimicrobial additive triclosan is a liver tumor promoter. PNAS 11(48):17200-17205

61. Zhang H, Shen K, Wu R, Li Z, Wang X, Wang D, Zhan M, Xu W, Gao Y, Lu L (2021a) Occurrence and distribution of neonicotinoids and characteristic metabolites in paired urine and indoor dust from young adults: Implications for human exposure. Environ Res 199:111175

10.1016/j.envres.2021.111175

62. Zhang H, Zhang N, Zhou W, Zeng X, Wang X, Zhan M, Xu W, Huang Y, Lu L, Li Z, et al. (2021b) Profiles of neonicotinoid insecticides and their metabolites in paired saliva and periodontal blood samples in human from South China: Association with oxidative stress markers. Ecotox Environ Safe 212:112001 10.1016/j.ecoenv.2021.112001

63. Zhang H, Zhu K, Du J, Ou M, Hou J, Wang D, Wang J, Zhang W, Sun G, (2021c) Serum concentrations of neonicotinoids and their characteristics metabolites in elderly population from South China: Association with osteoporosis. Environ Res 111772 10.1016/j.envres.2021.111772

64. Zhang N, Wang B, Zhang Z, Chen X, Huang Y, Liu Q, Zhang H (2021) Occurrence of neonicotinoid insecticides and their metabolites in tooth samples collected from south China: Associations with periodontitis. Chemosphere 264:128498 10.1016/j.chemosphere.2020.128498

65. Zhang Q, Lu Z, Chang C, Yu C, Wang X, Lu C (2019) Dietary risk of neonicotinoid insecticides through fruit and vegetable consumption in schoolage children. Environ Int 126:672-681 10.1016/j.envint.2019.02.051

66. Zhang Q, Wang X, Rao Q, Chen S, Song W (2020) Imidacloprid dissipation, metabolism and accumulation in Agaricus bisporus fruits, casing soil and compost and dietary risk assessment. Chemosphere 254:126837 10.1016/j.chemosphere.2020.126837

67. Zhang T, Song S, Bai X, He Y, Zhang B, Gui M, Kannan K, Lu S, Huang Y, Sun H (2019) A nationwide survey of urinary concentrations of neonicotinoid insecticides in China. Environ Int 132:105114 10.1016/j.envint.2019.105114

68. Zhao B, Shen H, Liu F, Liu S, Niu J, Guo F, Sun X (2012) Exposure to organochlorine pesticides is an independent risk factor of hepatocellular carcinoma: A case - control study. J Expo Sci Env Epid 22:541-548

\section{Figures}




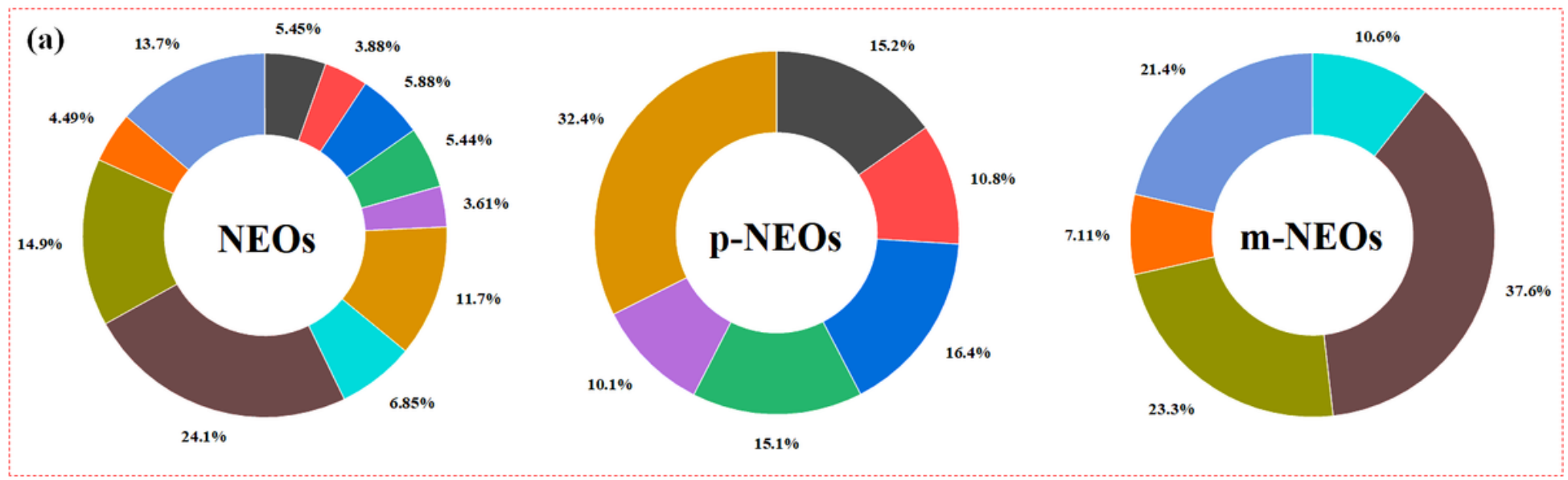

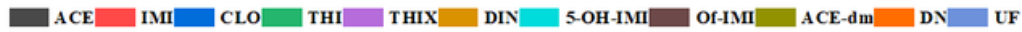

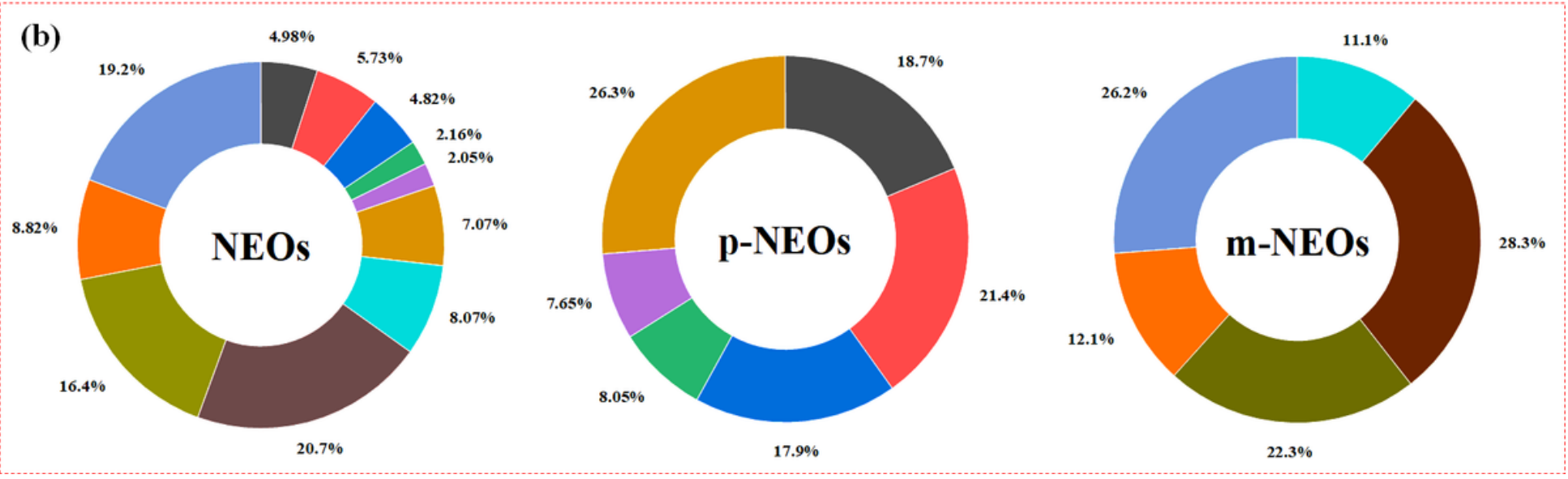

Figure 1

Composition profiles of NEOs and their metabolites in blood samples, as stratified by health (plot a) and liver cancer (plot b) populations. 


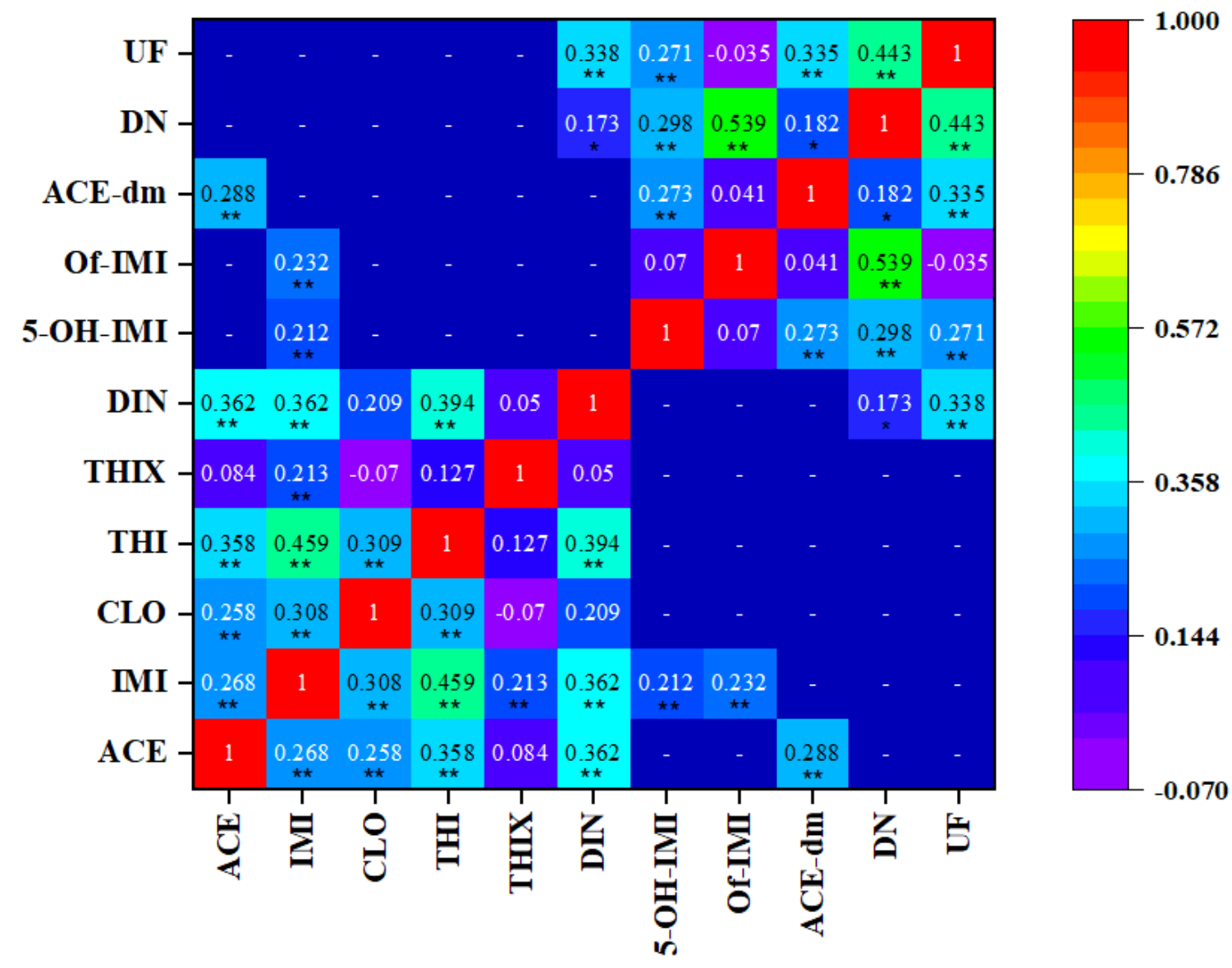

Figure 2

Pearson correlations among concentrations of NEOs and their metabolites in blood samples. The log-transformed concentrations were used in these analyses; the single asterisk $(*)$ and double asterisk $\left(^{* *}\right)$ represented the $p<0.05$ and $p<0.01$, respectively. 
(a)

age $1 \square$ age $2 \square$ age 3
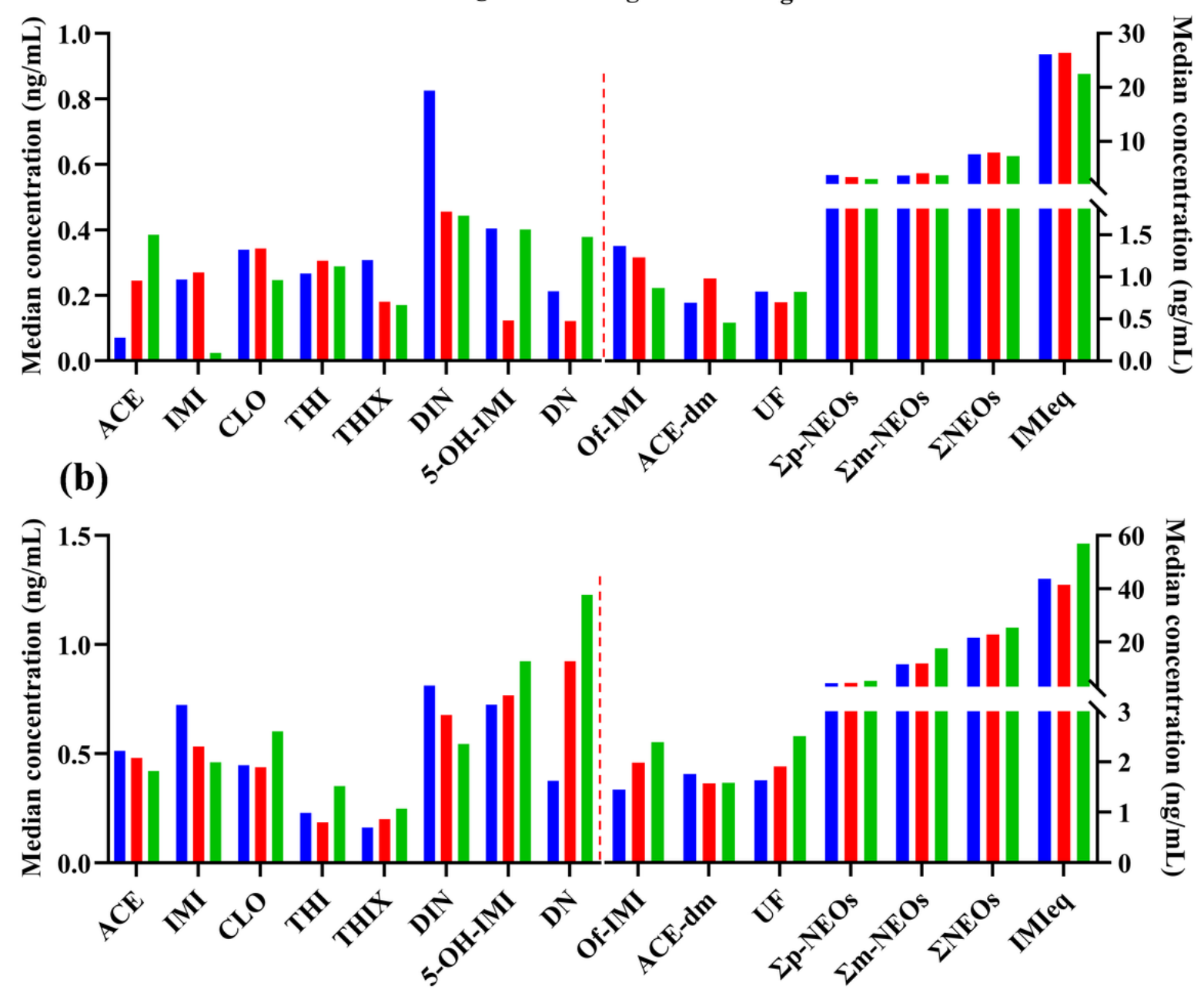

Figure 3

The median concentrations of NEOs and their metabolites in blood samples collected from health (plot a) and liver cancer (plot b) populations in China, as stratified by age. Age 1, age 2, age 3 represent $<40$ years, $40-60$ years, and $>60$ years age group, respectively. 

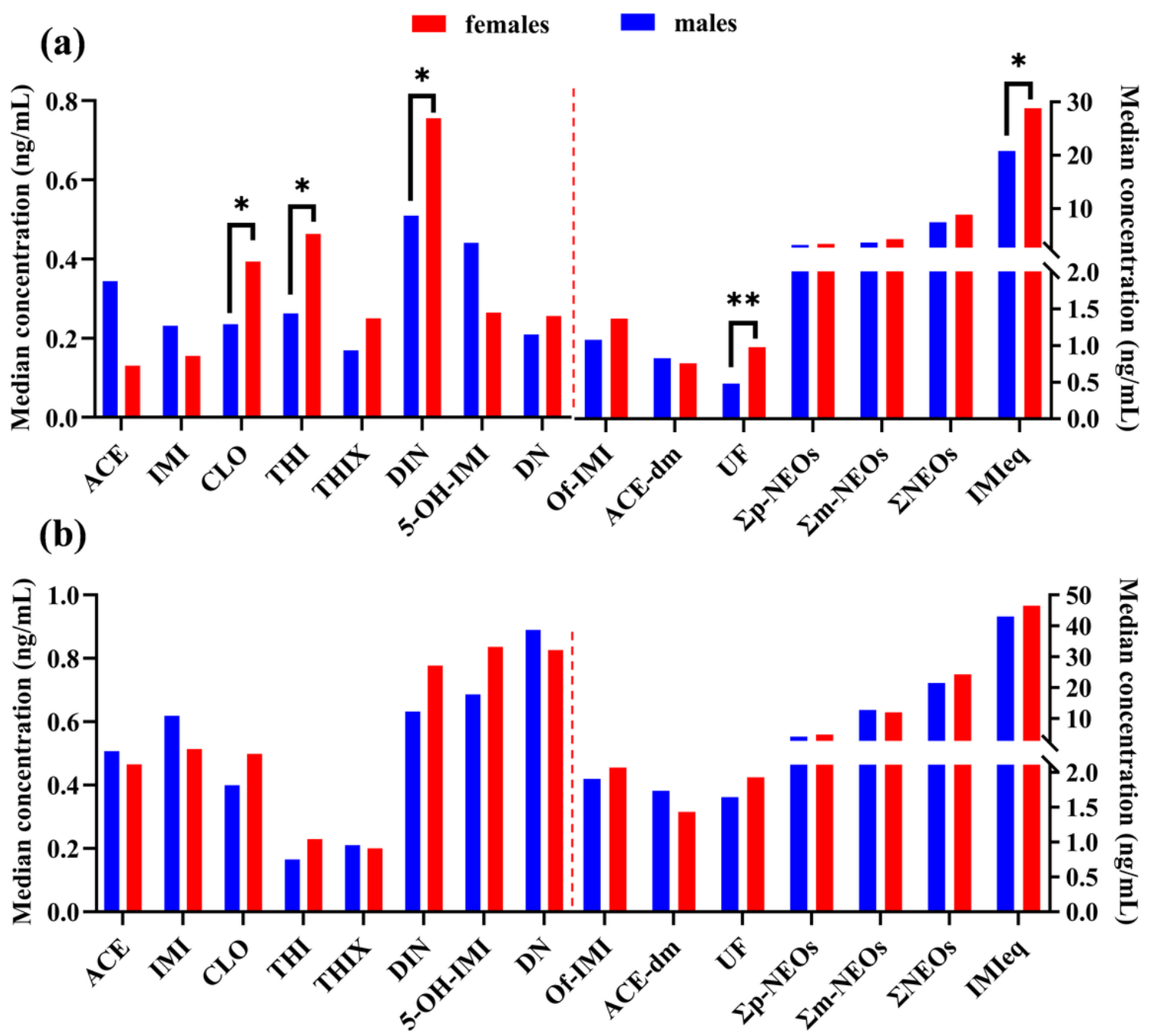

Figure 4

The median concentrations of NEOs and their metabolites in blood samples collected from health (plot a) and liver cancer (plot b) populations in China, as stratified by gender. Double asterisk $\left(^{* \star}\right)$ represents significant difference with $p$ value lower than 0.01 (Mann Whitney U test); single asterisk (*) represents significant different with $\mathrm{p}$ value lower than 0.05 (Mann Whitney U test). 


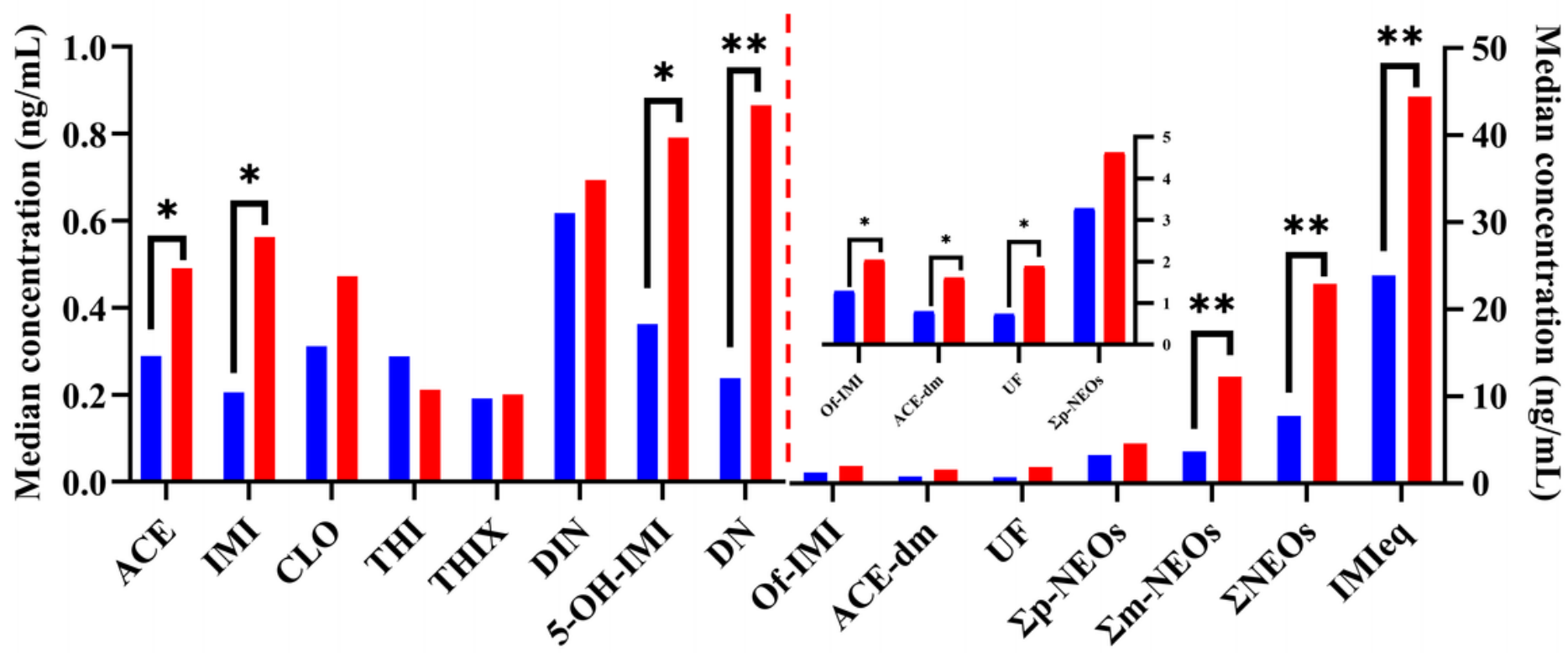

Figure 5

The median concentrations of NEOs and their metabolites in blood samples collected from health and liver cancer populations in China. Double asterisk (**) represents significant difference with p value lower than 0.01 (Mann Whitney U test); single asterisk (*) represents significant different with $p$ value lower than 0.05 (Mann Whitney U test).

\section{Supplementary Files}

This is a list of supplementary files associated with this preprint. Click to download.

- SupplementaryMaterialNEOsblood.docx 